University of Nebraska - Lincoln

DigitalCommons@University of Nebraska - Lincoln

Faculty Publications, Department of Psychology

Psychology, Department of

February 2003

\title{
Sociocognitive and Behavioral Correlates of a Measure of Prosocial Tendencies for Adolescents
}

\author{
Gustavo Carlo \\ University of Nebraska-Lincoln, carlog@missouri.edu \\ Anne Hausmann \\ University of Nebraska-Lincoln \\ Stacie Christiansen \\ University of Nebraska-Lincoln \\ Brandy A. Randall \\ University of Nebraska-Lincoln
}

Follow this and additional works at: https://digitalcommons.unl.edu/psychfacpub

Part of the Psychiatry and Psychology Commons

Carlo, Gustavo; Hausmann, Anne; Christiansen, Stacie; and Randall, Brandy A., "Sociocognitive and Behavioral Correlates of a Measure of Prosocial Tendencies for Adolescents " (2003). Faculty Publications, Department of Psychology. 4.

https://digitalcommons.unl.edu/psychfacpub/4

This Article is brought to you for free and open access by the Psychology, Department of at DigitalCommons@University of Nebraska - Lincoln. It has been accepted for inclusion in Faculty Publications, Department of Psychology by an authorized administrator of DigitalCommons@University of Nebraska - Lincoln. 


\title{
Sociocognitive and Behavioral Correlates of a Measure of Prosocial Tendencies for Adolescents
}

\author{
Gustavo Carlo \\ Anne Hausmann \\ Stacie Christiansen \\ Brandy A. Randall \\ University of Nebraska-Lincoln
}

\begin{abstract}
The present study was designed to examine the psychometric properties of a multidimensional measure of prosocial behaviors to use with early adolescents and middle adolescents. One hundred thirty-eight students $\overline{\mathrm{X}}$ age $=15.8$ years; 80 girls; 70\% White, non-Hispanic) from a public middle school and high school completed measures of prosocial moral reasoning, sympathy, perspective taking, aggression, ascription of responsibility, social desirability, verbal skills, and a revised prosocial tendencies measure (PTM-R). The questionnaires were completed in two sessions each separated by a 2-week time span (to assess testretest reliability of the PTM-R). Moreover, teacher ratings of adolescents' generosity and helpfulness toward others were obtained. Analyses were conducted separately for early adolescents and middle adolescents and results showed adequate reliability and evidence of validity for PTM-R. Discussion focused on individual differences in prosocial behaviors among early adolescents and middle adolescents and the need to differentiate among differing types of prosocial behaviors.
\end{abstract}

Keywords: measurement; moral development; moral cognitions; moral emotions; prosocial behavior

Despite popular conceptions that adolescents in the United States engage in many risky and antisocial behaviors, there is recognition among scholars that most adolescents engage in prosocial behaviors (i.e., behavior that benefits

\footnotetext{
The authors appreciated the assistance of Randy Ernst, Rick Koenig, Mariah Meyer, Cheri Moeser, Neil Nicolaus, and the cooperation of the teachers, staff, parents, and students of Culler Middle School and Lincoln High School. The John Templeton Foundation provided funding support for this project to Gustavo Carlo.
}

Journal of Early Adolescence 23:1 (Feb 2003), pp. 107-134 DOI: 10.1177/0272431602239132 Copyright (C) 2003 Sage Publications. Used by permission. 
others; Carlo \& Randall, 2001). In recent years, there has been increasing interest in adolescents' positive social behaviors, especially in understanding the characteristics of adolescents who engage frequently in those behaviors. Much of that recent interest stems from scholars and researchers who postulate that the development of effective intervention programs aimed at reducing risky and antisocial behaviors will necessitate an understanding of positive social development (Consortium on the Promotion of Social Competence, 1994).

Early adolescence is a particularly important age period for understanding prosocial development because many young people are presented with new opportunities for engaging in prosocial behaviors (Carlo, Fabes, Laible, \& Kupanoff, 1999). For example, a large number of children become engaged in voluntary activities once they enter adolescence, and there is evidence that the number of adolescents who volunteer in charity organizations has increased substantially in the past decade (Independent Sector, 1999). However, although much is known with regard to the development of prosocial behaviors in young children, relatively less is known with regard to the development of those behaviors during adolescence. One reason for the relative scarcity of research on prosocial development during adolescence is the lack of psychometrically adequate measures of prosocial behaviors for use with that population (Carlo \& Randall, 2001). In the present study, the psychometric properties of a measure of prosocial behaviors to use with early adolescents and middle adolescents are reported.

The opportunities for, and diversity of, prosocial behaviors increase as children enter adolescence, partly due to new and emerging interpersonal relationships, cognitive and emotive development, and changes in the social context (Carlo, Eisenberg, \& Knight, 1992; Carlo, Fabes et al., 1999; Fabes, Carlo, Kupanoff, \& Laible, 1999). For example, new and modified relationships with peers and adult figures (e.g., teachers, parents) can impact adolescents' prosocial behaviors by providing new targets of helping and exposure to new values, belief systems, or behaviors. Furthermore, many teachers require students to engage in service learning activities and many adolescents (particularly older adolescents) voluntarily, or with parental encouragement, join service clubs (Fletcher, Elder, \& Mekos, 2000). Adolescents also have greater mobility that affords additional opportunities for engaging in behaviors that benefit others.

In addition to those new social opportunities, adolescents undergo a series of changes in sociocognitive and socioemotive skills. For example, potential for increases in abstract thinking skills, forethought, perspective taking, and hypothetical-deductive reasoning skills are associated with increases in moral reasoning and sympathy (Hoffman, 1991; Selman, 1980; Tomlinson-Keasey \& Keasey, 1974). In turn, those sociocognitive and socioemotive skills are linked to prosocial and moral behaviors (Blasi, 1980; Eisenberg \& Fabes, 1998; Roberts \& Strayer, 1996; Thoma, Rest, \& Davison, 1991). The combination of those and other personal and social contextual changes no doubt contribute to individual differences in prosocial behaviors during adolescence.

Relatively high stability of prosocial tendencies during adolescence has been revealed by researchers (e.g., Davis \& Franzoi, 1991). However, research on the correlates of prosocial behaviors show wide individual differences in adolescents who exhibit those behaviors. For example, researchers have provided evidence that adolescents who reported higher levels of sympathy and perspective taking (i.e., understanding another's thoughts, feelings, and situation) reported higher levels of prosocial responding (Estrada, 1995; Roberts \& Strayer, 1996). Other researchers have shown that adolescents who are rated by teachers as generous and helpful toward others tend to score higher on prosocial moral reasoning (Carlo, Koller, Eisenberg, Da Silva, \& Frohlich, 1996; see also Eisenberg, Carlo, Murphy, \& Van Court, 1995). Crick and Nelson (1999) reported that adolescents who were rated by their peers as more prosocial were more likely to make benign attributions in ambiguous situations (e.g., judge whether a peer, intentionally or accidentally, rolled a basketball under their feet and caused them to fall). That research has indicated that social information processes and skills are important correlates of prosocial behaviors.

However, in previous studies, there have been at least two limitations to understanding prosocial development in adolescence. One limitation is that researchers who examine prosocial development in adolescence have not investigated possible differences between early adolescents and middle adolescents in the correlates of prosocial behaviors. Indeed, based on cognitive developmental and social ecological theories, it might be expected that younger adolescents' and older adolescents' prosocial development would be associated with age-specific correlates. Furthermore, because perspective-taking skills still might be developing during early adolescence, such skills might be related more strongly to prosocial behaviors in early adolescence rather than in late adolescence. To explore the pattern of correlates of prosocial behaviors in early adolescence and in middle adolescence, the pattern of relations in those two adolescent age periods was compared.

Another limitation in previous studies stems from the fact that researchers often do not distinguish among the differing types of prosocial behaviors. For example, in many previous studies, researchers used global measures that did 
not differentiate among such varied behaviors as helping to pick up dropped items, comforting a hurt person, donating money to charity, and holding a door open for a stranger. Alternatively, researchers use general measures such as teacher or peer ratings of kindness, helpfulness, cooperation, or generosity. Other researchers have used measures that might have tapped into skills or competencies such as communication skills, self-efficacy, self-esteem, or social acceptance-dimensions that assess the broader domain of social competence. Although global measures of prosocial behaviors might be useful for assessing general prosocial tendencies, because some specific types of prosocial behaviors are interrelated and because prosocial behaviors might be construed as one aspect of social competence, it might be expected that there are differing correlates for differing types of prosocial behaviors.

Theorists (Bandura, 1986) note that specific cognitive processes (e.g., selfefficacy) are associated with specific social behaviors. Similarly, other scholars emphasize the importance of task-specific cognitive skills required to understand performance on specific tasks (Knight, Johnson, Carlo, \& Eisenberg, 1994). Based on those conceptual notions, it might be expected that specific individual and social contextual characteristics might be related to specific types of prosocial behaviors. Previous research has indicated that there are individual differences in the extent to which individuals help in emotionally evocative and crisis situations (Carlo, Eisenberg, Troyer, Switzer, \& Speer, 1991), in front of others, anonymously, when asked to (Eisenberg, Cameron, Tryon, \& Dodez, 1981), and when there is a cost to the self (Eisenberg et al., 1999; Schroeder, Penner, Dovidio, \& Piliavin, 1995; see Batson, 1991; Staub, 1978). For example, individuals who frequently engage in altruistic forms of helping (i.e., behaviors intended primarily to benefit others with little regard for self consequences) are prone to sympathy, higher level moral reasoning and perspective taking, ascribe social responsibility to themselves, and exhibit fewer aggressive behaviors (Eisenberg \& Fabes, 1998).

Individuals who frequently help in emotionally evocative situations also are prone to sympathy and higher levels of moral reasoning and perspective taking (Carlo et al., 1991). In contrast, adolescents who frequently engage in helping behaviors in front of others have been shown to be most concerned with gaining other people's approval (Carlo \& Randall, 2002); thus, approval-oriented prosocial moral reasoning was expected to be related significantly and positively to public prosocial behaviors. However, those relations might differ between early adolescents and middle adolescents because sociocognitive development places an upper limit on facilitating prosocial behaviors that require those skills. That can cause greater variability in sociocognitive skills of early adolescents as compared to middle adolescents. Therefore, perspec- tive taking and high levels of moral reasoning would be expected to be related significantly and positively to those prosocial behaviors, particularly in early adolescence.

As a result of capital growth, work opportunities, and greater social mobility, many adolescents have increased opportunities to help others anonymously (e.g., donating money), to engage in compliant helping, and in emergency situations. However, although there is some research on the correlates of those latter types of prosocial behaviors in childhood (especially compliant and anonymous types of helping) and in college students (especially helping in emergency situations; see Batson, 1991; Eisenberg \& Fabes, 1998; Staub, 1978), little is known with regard to the characteristics of young adolescents who help under those circumstances. Therefore, there were no specific a priori hypotheses on the correlates of compliant, anonymous, and dire types of helping during early adolescence or middle adolescence.

In summary, several hypotheses were developed. It was expected that specific prosocial behaviors would be related differently to specific sociocognitive and socioemotive skills. Specifically, altruism and emotional prosocial behaviors would be related significantly and positively to sympathy, high levels of prosocial moral reasoning, and perspective taking (especially among early adolescents); whereas, public prosocial behaviors would be related significantly and positively to approval-oriented prosocial moral reasoning (a low level of prosocial moral reasoning). Significant and positive relations were expected between altruism and emotional prosocial behaviors and ascription of responsibility and other measures of prosocial behaviors; in contrast, negative relations were expected between aggression and altruism. No a priori hypotheses were developed on the sociocognitive and socioemotive correlates of dire, compliant, and anonymous prosocial behaviors. Weak and nonsignificant relations between the specific types of prosocial behaviors and social desirability, vocabulary skills, and personal distress were expected to indicate discriminant validity evidence. Moreover, it was expected that middle adolescents and girls would score higher on altruism than would early adolescents and boys and that boys would score higher on public prosocial behaviors than would girls.

\section{METHOD}

\section{Participants}

One hundred thirty-eight students $(\bar{X}$ age $=15.8$ years, $S D=1.60 ; 80$ girls, 58 boys; 70\% White/non-Hispanic, 10\% African American, 10\% other ethnic groups) from a public middle school and a senior high school in the 
Midwestern United States participated in the current study. Approximately $49 \%$ of their mothers had some college education, $44 \%$ had a high school (or equivalent) diploma, and 7\% did not graduate from high school.

To examine the pattern of relations by age group, a median split of age was conducted to divide the sample into early adolescents and middle (those older than 16 years of age $)$ adolescents. There were 80 early adolescents $(\bar{X}$ age $=14.7$ years, $S D=1.17 ; 49$ girls, 31 boys $)$ and 58 middle adolescents $(\bar{X}$ age $=17.3$ years, $S D=.50 ; 31$ girls, 27 boys). Students were recruited by sending letters to their parents to obtain active informed consent. The cooperating schools received a monetary donation to the general school fund and a summary report of the findings, and participating teachers received a $\$ 10$ gift certificate. Student participation was voluntary.

\section{Procedure}

After obtaining Institutional Review Board approval from the university, the school district, and the principals of the schools, researchers recruited from classrooms (data were collected in Spring 2000). All students were told that the study was designed to assess the "way teenagers think and act in typical social situations." Students who expressed interest were asked to take recruitment letters and informed consent forms to their parents. Parents were told that the purpose of the study was to examine "tendencies people may have to think and react in specific ways on a day-to-day basis." After obtaining parental consent, students who assented completed questionnaires in two sessions in their classrooms (teachers were not present during administration). Each session lasted approximately 30 to 40 minutes and students participated in groups of approximately 15 to 25 students.

In the first session, participants were administered the following measures (see description of measures below) in a randomized order: the PTM-R, sympathy, prosocial moral reasoning, global prosocial behavior, and suppression of aggression. At the second session, approximately 2 weeks later, participants were readministered the PTM-R to assess test-retest reliability. In addition, they were administered the empathic accuracy, ascription of responsibility, vocabulary skills, and social desirability scales. All participants were then debriefed and thanked.

\section{Materials}

Prosocial Tendencies Measure-Revised. The Prosocial Tendencies Measure (PTM) originally was developed to assess self-report of six types of prosocial behaviors among college individuals (Carlo \& Randall, 2002). Items for the PTM were selected from previously developed prosocial disposition and behavior scales (Johnson et al., 1989; Rushton, Chrisjohn, \& Fekken, 1981; Schroeder et al., 1995) and from responses to prosocial moral reasoning interviews (Eisenberg et al., 1995). Carlo and Randall (2001) reported adequate model fit coefficients using confirmatory factor analysis with college students.

The PTM was modified to use with younger adolescents in the present study. To develop the version for younger adolescents, a focus group (10 adolescents, ages 11 through 16) of adolescents was asked to evaluate the original PTM items for clarity and relevance and asked for suggestions to improve the items. After the slight revisions in the wording (for simpler vocabulary) and after adding two items based on suggestions from the focus group, the Prosocial Tendencies Measure-Revised (PTM-R) consists of 25 items that assess six types of prosocial behaviors.

The six types of prosocial behaviors in the PTM-R include public, anonymous, dire, emotional, compliant, and altruism (see appendix). Public prosocial behaviors were defined as behaviors intended to benefit others enacted in the presence of others (four items; sample item, "I can help others best when people are watching me"). Anonymous prosocial behaviors were defined as the tendency to help others without other people's knowledge (five items; "I think that helping others without them knowing is the best type of situation"). Dire prosocial behaviors refer to helping others under emergency or crisis situations (three items; "I tend to help people who are in real crisis or need"). Emotional prosocial behaviors are behaviors intended to benefit others enacted under emotionally evocative situations (five items; "I respond to helping others best when the situation is highly emotional"). Compliant prosocial behaviors refer to helping others when asked to (two items; "When people ask me to help them, I don't hesitate"). Altruism refers to helping others when there is little or no perceived potential for a direct, explicit reward to the self (six items; "I often help even if I don't think I will get anything out of helping"). Data were coded such that high scores on each of these scales reflect a stronger endorsement. Scoring key and instructions for the PTM-R can be obtained on request from the first author.

Prosocial moral reasoning. The paper-and-pencil measure of prosocial moral reasoning (PROM) was administered (Carlo et al., 1992; Eisenberg et al., 1995). Five stories were administered, each containing a conflict between a protagonist's needs and desires and those of (an)other(s). The following is a sample story from the PROM: 
One day Mary was going to a friend's party. On the way, she saw a girl who had fallen down and hurt her leg. The girl asked Mary to go to the girl's house and get her parents so the parents could come and take her to the doctor. But if Mary did run and get the girl's parents, Mary would be late to the party and miss the fun and social activities with her friends.

The participant was asked to read each story and indicate (a) whether the protagonist should help the needy other, (b) whether the protagonist should not help the needy other, or (c) whether they were unsure what the protagonist should do. Participants then were asked to rate on a 5 -point scale ( 1 = not at all through $5=$ greatly) the importance of the nine reasons why the protagonist should, or should not, help the needy other in the story.

In those stories, a representative sample of frequently reported prosocial moral reasons was selected for each story. Each of the stories included one hedonistic reason (Level 1 in the Eisenberg, 1986, schemata, which consists of simple hedonistic or direct reciprocity reasoning; e.g., "It depends how much fun Mary expects the party to be, and what sorts of things are happening at the party"), one needs-oriented reason (Level 2; e.g., "It depends whether the girl really needs help or not"), one approval-oriented reason (Level 3; e.g., "It depends whether Mary's parents and friends will think she did the right or she did the wrong thing"), and one stereotyped reason (Level 3; e.g., "It depends if Mary thinks it's the decent thing to do or not"). Each story also contained one internalized reason, which reflected a higher level of reasoning (Level 4 and 5), and consisted of sympathy, role-taking, positive or negative affect, generalized reciprocity, or internalized value (e.g., "It depends how Mary would feel about herself if she helped or not"). The sixth reason was a lie/nonsense item (e.g., "It depends whether Mary believes in people's values of metacognition or not"). Carlo et al. (1992) report that lie/nonsense items can be used to screen out participants who strongly endorsed these items. However, only one participant in the present study scored at or above $2 S D$ above the mean of the lie scale (the criteria suggested by Carlo et al., 1992). However, dropping this one participant from the analyses did not appreciably change the results. Thus, data from all participants were retained.

Scores were derived by summing the items across the five stories for each of the five types of prosocial moral reasoning to obtain a frequency score. The frequency PROM scores were transformed to proportion PROM scores by dividing each of the scores for the five types of moral reasoning by the sum of frequency PROM scores. The proportion score reflects a participant's preference for a particular reasoning type relative to the other reasoning types. There were five hedonistic items (Cronbach's alpha coefficient $=.74$ ), five needs-oriented items (Cronbach's alpha coefficient $=.71$ ), five approval-oriented items
(Cronbach's alpha coefficient $=.86)$, five stereotypic items (Cronbach's alpha coefficient $=.83$ ), and five internalized-level items (Cronbach's alpha coefficient $=.75)$. Evidence for the reliability and validity of the PROM has been reported elsewhere (e.g., Carlo et al., 1996; Eisenberg et al., 1995).

Global prosocial behavior. The 20-item, self-report measure developed by Rushton et al. (1981) was used to obtain an overall measure index of prosocial behavior. Participants were asked to rate the frequency of various behaviors on a 5 -point scale where 1 = never and 5 = very often (e.g., "I have delayed an elevator and held the door open for a stranger"). Researchers have reported adequate reliability and validity for use with adolescents (e.g., Carlo, Roesch, \& Melby, 1998; Eisenberg et al., 1995). Cronbach's alpha coefficient in the present study was .88 .

Empathy. Three subscales of a multidimensional measure of empathy (Davis, 1983) were used to examine perspective taking (e.g., "I try to look at everybody's side of a disagreement before I make a decision"; seven items, Cronbach's alpha coefficient $=.83$ ); empathic concern, hereafter referred to as sympathy (e.g., "I am often quite touched by things that I see happen"; seven items, Cronbach's alpha coefficient = .76); and personal distress (e.g., "In emergency situations, I feel anxious and ill-at-ease"; seven items, Cronbach's alpha coefficient $=.60$ ). Participants were asked to rate how well each item describes them on a 5 -point scale where $1=$ does not describe me well and $5=$ describes me very well. Several researchers have presented evidence of adequate reliability and validity (e.g., Davis \& Franzoi, 1991; Laible, Carlo, \& Raffaelli, 2000).

Social desirability. A shortened, 25-item version of the Crowne and Marlowe (1964) scale was administered to assess individuals' tendency to present themselves in a positive manner to others. Participants were asked to rate whether each item was true or false as it pertained to themselves (sample items, "I always try to practice what I preach" and "There have been occasions when I felt like smashing things" [reverse coded]). Reliability and validity evidence for this version of the scale has been presented in studies (e.g., Carlo et al., 1992; Eisenberg et al., 1995). Cronbach's alpha coefficient in the present study was .75.

Aggression. Participants also completed the Suppression of Aggression subscale from the Weinberger Adjustment Inventory (Weinberger, 1991). The five items were rated on a 5 -point scale where $1=$ does not describe me and 
$5=$ describes me very well (e.g., "I lose my temper and 'let people have it' when I'm angry"). Items were reversed so that a high score indicated higher levels of aggression. Weinberger and colleagues (Weinberger, 1995; Weinberger \& Bartholomew, 1996; Weinberger \& Gomes, 1995) have reported adequate psychometric properties, including test-retest reliabilities and validity, of the Suppression of Aggression subscale in samples with adolescents (see also Carlo, Fabes et al., 1999). Furthermore, researchers previously have found that self-report measures of aggression are associated significantly with behavioral observations and teacher and peer ratings of aggression (e.g., Achenbach, 1991). Cronbach's alpha coefficient in the present study was .86.

Ascription of Responsibility. The 28-item Ascription of Responsibility Scale (Schwartz, 1968; Schwartz \& Howard, 1984) was used to assess adolescents' beliefs about social obligation and responsibility. The items were rated on a 5point scale where 1 = strongly agree and $5=$ strongly disagree (e.g., "Your obligations can never justify forgetting the needs of others"). Items were recoded so that a high score indicated a high sense of social obligation and responsibility. Cronbach's alpha coefficient in the present study was .82. In addition, researchers have found adequate reliability and validity evidence (e.g., Schroeder et al., 1995).

Empathic Accuracy. A 17-item Empathic Accuracy Scale (Ickes, Bissonnette, Garcia, \& Stinson, 1990) was administered to assess adolescents' ability to accurately understand and anticipate another's situation (similar to perspective taking). The items were rated on a 4-point scale where $1=$ not like me at all and 4 = like me a lot (sample item, "I can tell how people are feeling long before they say anything about it"). Cronbach's alpha coefficient in the present study was .77.

Quick Word Test (QWT). To assess vocabulary skills, a shortened, 40-item version of the QWT (Borgatta \& Corsini, 1960) was used. The students received a score based on the number of correct responses (these scores were not standardized within each grade). The QWT has shown strong correlations with various measures of intelligence and has demonstrated good stability and validity evidence (e.g., Borgatta \& Corsini, 1960).

Teacher ratings of generosity and helpfulness. Toward the end of the academic year, teachers were asked to rate each participating adolescent from their classroom on their generosity and helpfulness on a scale from 1 (almost never) through 7 (almost always). The generosity and helpfulness ratings were standardized within the classroom. Teacher ratings of helpfulness were correlated significantly with ratings of generosity, $r(127)=.82, p<.001$ (data from eight students were missing because the teachers did not complete those students' ratings). Thus, the standardized scores for generosity and helpfulness were summed and averaged to create a composite of generosity/ helpfulness.

\section{Data Analytic Approach}

To examine the psychometric properties of the PTM-R for both early adolescents and middle adolescents, all analyses were conducted separately for each age group. After conducting descriptive statistical analyses, the internal consistency of the PTM-R was examined by conducting Cronbach's alpha analyses on each of the PTM-R subscales. To assess the reliability of each subscale across time, test-retest reliabilities on each of those subscales were conducted by a series of correlational analyses. Correlational analyses were conducted also to examine the interrelations among the PTM-R subscales and to examine the relations of the PTM-R to other theoretically relevant variables. A series of hierarchical multiple regression analyses was conducted to investigate age and gender differences in the PTM-R subscales.

\section{RESULTS}

\section{Descriptive Statistics and Internal Consistency of the PTM-R Subscales}

The means and standard deviations for the PTM-R subscales are presented separately for each adolescence age group in Table 1 . Middle adolescents reported altruistic prosocial tendencies the most, followed by compliant, dire, emotional, anonymous, and public, respectively. In contrast, early adolescents reported altruistic prosocial tendencies the most, followed by compliant and emotional, then dire, anonymous, and public, respectively (tests of age effects will be reported).

As can be seen in Table 1, the range of Cronbach's alpha coefficients for the PTM-R subscales for the middle adolescents was from .75 through .86 $(\bar{X}=.80)$. The range of Cronbach's alpha coefficients for early adolescents was from .59 through $.86(\bar{X}=.75)$. The range for the 2 -week test-retest reliabilities of the PTM-R subscales for middle adolescents was from .56 through .82 $(\bar{X}=.71)$ (see Table 1$)$. The range for the 2 -week, test-retest reliabilities of the PTM-R subscales for early adolescents was from .54 through $.76(\bar{X}=.67)$. 


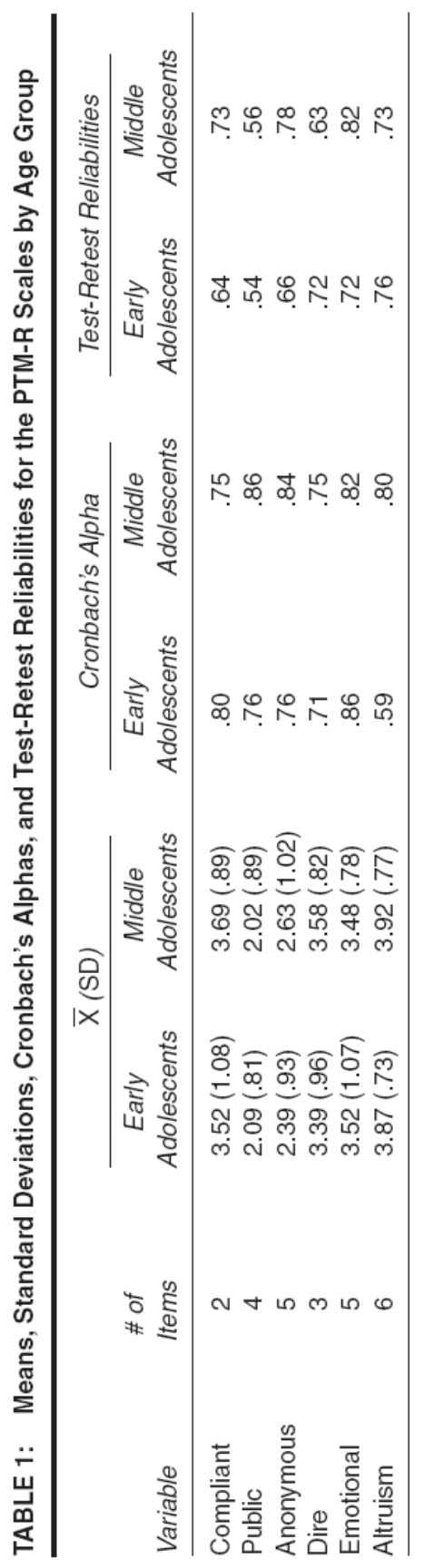

TABLE 2: Interrelations Among the PTM-R Subscales By Age Group

\begin{tabular}{lcccccc}
\hline Variable & Compliant & Public & Anonymous & Dire & Emotional & Altruism \\
\hline Compliant & - & .10 & .09 & $.60^{\star \star}$ & $.70^{\star \star}$ & .15 \\
Public & .09 & - & -.07 & .10 & .25 & -.22 \\
Anonymous & $.30^{\star \star}$ & $.35^{\star \star}$ & - & .22 & .16 & .06 \\
Dire & $.61^{\star \star}$ & $.33^{\star \star}$ & $.44^{\star \star}$ & - & $.60^{\star \star}$ & .04 \\
Emotional & $.61^{* \star}$ & $.27^{\star \star}$ & $.36^{\star *}$ & $.80^{\star \star}$ & - & .19 \\
Altruism & $.32^{\star \star}$ & $-.53^{\star \star}$ & -.06 & -.02 & -.02 & - \\
\hline
\end{tabular}

NOTE: Coefficients above the diagonal are data for middle adolescents. Coefficients below the diagonal are data for early adolescents.

${ }^{*} p<.05{ }^{* \star} p<.01$.

\section{Interrelations Among the PTM-R Subscales}

To examine the structure of prosocial tendencies during early adolescence as compared with middle adolescence, correlational analyses were conducted for each age group. The pattern of relations among the PTM-R differed for each adolescence age group (see Table 2). Among middle adolescents, compliant prosocial tendencies were positively related to dire and emotional prosocial tendencies, which also were positively related to each other. Thus, there were relatively few significant relations for middle adolescents. Among early adolescents, compliant prosocial tendencies were positively related to anonymous, dire, emotional, and altruistic prosocial tendencies. Public prosocial tendencies were positively related to dire and emotional prosocial tendencies and negatively related to altruistic prosocial tendencies. Anonymous prosocial tendencies were positively related to dire and emotional prosocial tendencies. Dire prosocial tendencies were positively related to emotional prosocial tendencies. Thus, there were relatively more significant relations among the PTM-R subscales for early adolescents.

\section{Effects of Age and Gender on the PTM-R}

A series of hierarchical multiple regressions was conducted to examine the effects of gender and age on the PTM-R. In each of these analyses, in the first step the main effects of age (for these analyses, age was used as a continuous measure) and gender were entered. In the second step the age by gender interaction vector was entered. 
Effects of age and gender on prosocial tendencies. For altruistic prosocial tendencies, the first step accounted for a significant amount of systematic variance, $R^{2}=.09, F(2,132)=6.63, p<.01$. Both age and gender were significant predictors, such that middle adolescents and girls were more likely to report altruistic prosocial tendencies than were early adolescents and boys, standardized betas $=.17$ and -.26 , $p$ s $<.05$ and .01 , respectively. For public prosocial tendencies, the first set of predictors accounted for a significant amount of variance, $R^{2}=.05, F(2,132)=3.20, p<.04$. There was a significant main effect of gender, such that boys were more likely to report public prosocial tendencies than were girls, standardized beta $=.22, p<.02$. For emotional prosocial tendencies, there was a trend toward significance in systematic variance, $R^{2}=.04, F(2,132)=2.88, p<.06$. Gender was a significant predictor such that girls were more likely to report emotional prosocial tendencies than were boys, standardized beta $=-.20, p<.02$. For anonymous prosocial tendencies, there was a trend toward significance in systematic variance, $R^{2}=$ $.04, F(2,132)=2.88, p<.06$. Age was a significant predictor, such that middle adolescents were more likely to report anonymous prosocial tendencies than were early adolescents, standardized beta $=.20, p<.03$. There were no other significant effects of age and gender on prosocial tendencies.

\section{Relations of the PTM-R With Other}

\section{Theoretically Related Variables}

To examine the relations of the PTM-R with other theoretically related constructs, correlational analyses were separately conducted for early adolescents and middle adolescents (see Tables 3 and 4).

Relations with cognitive variables. For middle adolescents, altruistic prosocial tendencies were negatively related to approval-oriented prosocial moral reasoning and positively related to vocabulary scores (see Table 3). Emotional prosocial tendencies were positively related to internalized prosocial moral reasoning and empathic accuracy and negatively related to hedonistic moral reasoning. Dire prosocial tendencies were positively related to needsoriented and internalized prosocial moral reasoning and negatively related to approval-oriented prosocial moral reasoning. Furthermore, dire prosocial tendencies were positively related both to perspective taking and empathic accuracy.

Anonymous prosocial tendencies were negatively related to hedonistic prosocial moral reasoning. Public prosocial tendencies were positively related to approval-oriented prosocial moral reasoning. Compliant prosocial

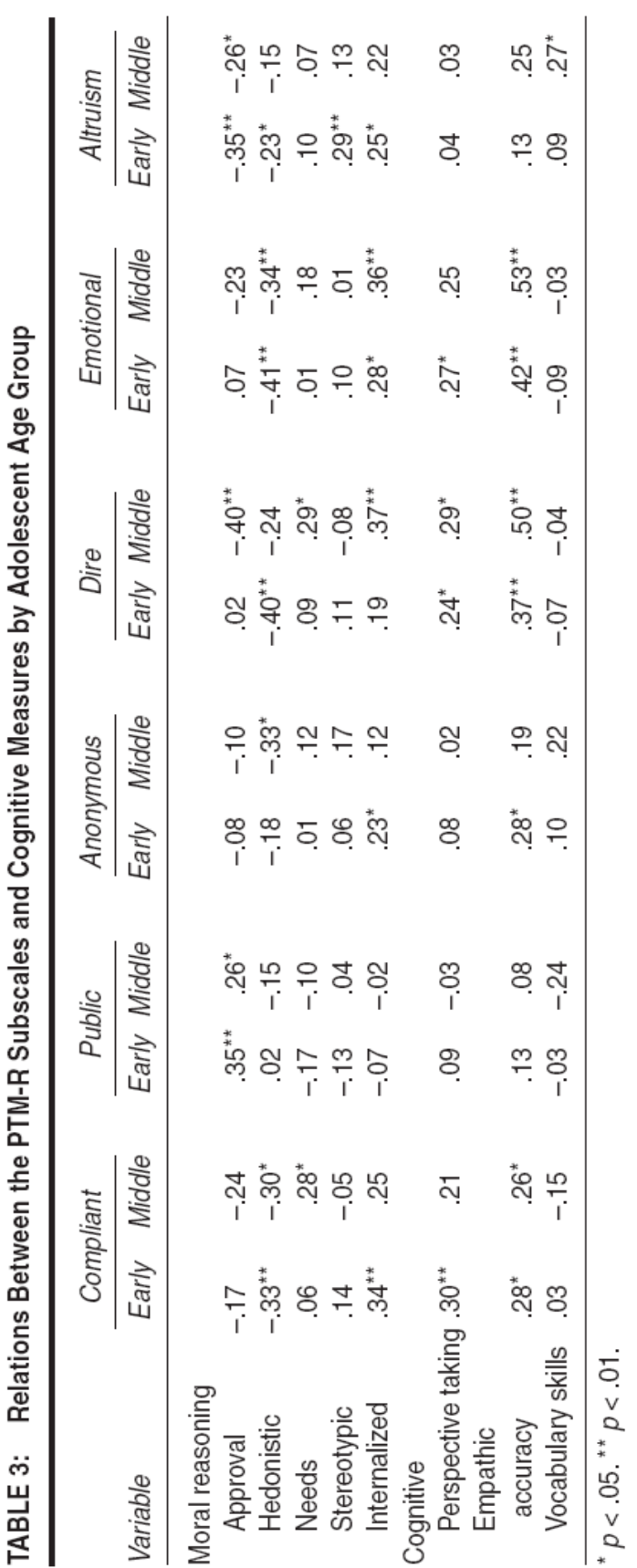




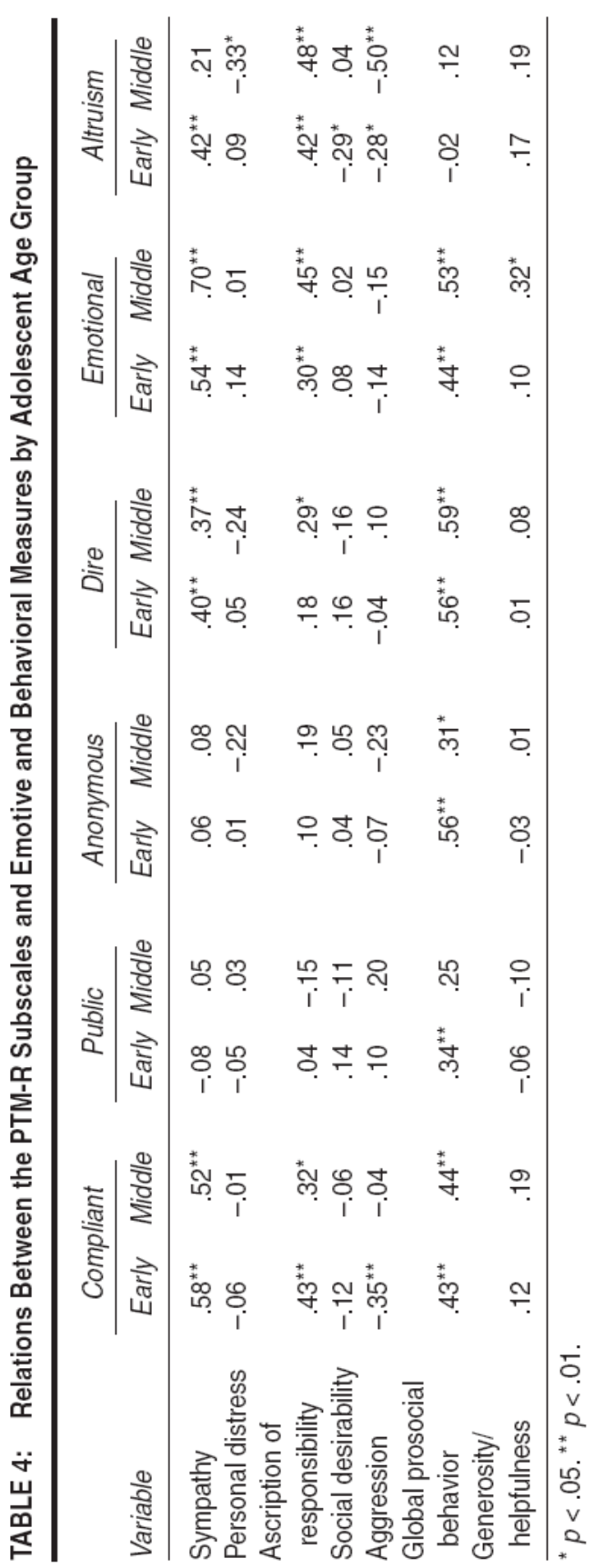

tendencies were negatively related to hedonistic prosocial moral reasoning and positively related to needs-oriented prosocial moral reasoning.

For early adolescents, altruistic prosocial tendencies were positively related to stereotypic and internalized prosocial moral reasoning (see Table 3). Furthermore, altruistic prosocial tendencies were negatively related to hedonistic and approval-oriented prosocial moral reasoning.

Emotional prosocial tendencies were positively related to internalized prosocial moral reasoning, perspective taking, and empathic accuracy, and negatively related to hedonistic moral reasoning. Dire prosocial tendencies were negatively related to hedonistic prosocial moral reasoning. Furthermore, dire prosocial tendencies were positively related to both perspective taking and empathic accuracy.

Anonymous prosocial tendencies were positively related to empathic accuracy and internalized prosocial moral reasoning. Public prosocial tendencies were positively related to approval-oriented prosocial moral reasoning. Compliant prosocial tendencies were negatively related to hedonistic prosocial moral reasoning and positively related to internalized moral reasoning, perspective taking, and empathic accuracy.

Thus, in general, there was a differing pattern of relations between the PTM-R subscales and the cognitive variables across the two age groups. Furthermore, as expected, the PTM-R was not significantly related to vocabulary skills (except to altruism for middle adolescents).

Relations with emotive variables. For middle adolescents, sympathy was positively associated with compliant, emotional, and dire prosocial tendencies (see Table 4). In contrast, personal distress was negatively related with altruism.

For early adolescents, sympathy was positively associated with compliant, emotional, dire, and altruistic prosocial tendencies (see Table 4). There were no significant relations between personal distress and the PTM-R subscales for this age group.

Relations with ascription of responsibility and social desirability. For middle adolescents, altruism, emotional, dire, and compliant prosocial tendencies were positively associated with ascription of responsibility (see Table 4). There were no significant relations between social desirability and the PTM-R subscales.

Similarly, for early adolescents, altruism, emotional, and compliant prosocial tendencies were positively associated with ascription of responsibility (see Table 4). Social desirability was not significantly related to the PTM-R subscales except negatively to altruism. 
Relations with global prosocial behavior, aggression, and teacher ratings of generosity/helpfulness. Convergent validity for the PTM-R was assessed by conducting correlational analyses between the PTM-R and other measures of prosocial behaviors. For middle adolescents, the global prosocial behavior scale was significantly and positively related to compliant, anonymous, dire, and emotional prosocial tendencies (see Table 4) but not to public prosocial tendencies or to altruism. Teacher ratings of generosity and helpfulness were significantly and positively related to emotional prosocial tendencies. Aggression was negatively related with altruistic prosocial tendencies and was not significantly related to any other prosocial tendencies.

For early adolescents, the global prosocial behavior scale was positively related to compliant, public, anonymous, dire, and emotional prosocial tendencies (see Table 4) but not to altruism. There were no significant relations between teacher ratings of generosity/helpfulness and the PTM-R. However, aggression was negatively related with compliant and altruistic prosocial tendencies and was not significantly related to any other prosocial tendencies.

To examine further the relations between the PTM-R and teacher ratings of generosity/helpfulness, teachers' ratings of generosity/helpfulness were correlated to a composite of the PTM-R. This analysis was conducted to assess whether a global, rather than a specific, index of the PTM-R might be significantly related to the global teacher ratings of generosity/helpfulness. The composite of the PTM-R was created by standardizing the subscale scores and summing. Cronbach's alpha coefficient for the PTM-R composite (25 items) was .87. These two global helping composites were interrelated significantly for early adolescents, $r(80)=.36, p<.001$, but not for middle adolescents, $r(55)=.21, p>.05$.

\section{DISCUSSION}

Overall, the findings yielded partial support for the reliability and validity of the PTM-R to use with early adolescents and middle adolescents. With regard to reliability evidence, the Cronbach's alpha coefficients and test-retest reliabilities indicated that the PTM-R subscales have adequate internal consistency and temporal stability across a 2 -week period. With regard to validity evidence, in general, the PTM-R subscales were related in a discriminant manner with other theoretically related variables. That is, in general, the PTM-R scales were significantly related with theoretically relevant variables (e.g., sympathy, perspective taking, moral reasoning) and nonsignificantly related with nontheoretically relevant variables (e.g., vocabulary skills, social desirability, personal distress). Perhaps more important, the findings revealed a differing pattern of relations between prosocial tendencies and other theoretically relevant variables for early adolescents and middle adolescents.

As expected, early adolescents who reported higher levels of prosocial moral reasoning were more likely to report altruistic tendencies. In contrast, early adolescents who reported lower levels of prosocial moral reasoning were less likely to report altruistic tendencies. These findings were consistent with cognitive-development theory that posits that altruism is facilitated by the reasoning based on strong internalized mores that consider the care and needs of others and that young children who are less concerned with approval and hedonistic motives are more likely to act altruistically (Eisenberg \& Fabes, 1998). For middle adolescents, altruism was negatively related to approval-oriented prosocial moral reasoning. Those findings indicated that middle adolescents with altruistic prosocial tendencies were less concerned with gaining other people's approval. However, it is important to note that there were no significant relations between altruism and perspective taking. Some scholars have suggested that perspective taking (i.e., cognitively understanding another's situation) is not sufficient to act altruistically and actually sometimes is used to manipulate and take advantage of others. Perspective taking might not be a strong predictor of helping without a motive (e.g., sympathy) to assist others (see Hoffman, 1991).

Consistent with the hypotheses, higher levels of altruism were linked to higher levels of ascription of responsibility and to lower levels of aggression for both early adolescents and middle adolescents. In addition, higher levels of sympathy were associated with higher levels of altruism for early adolescents. Those findings indicated that increases in adolescents' willingness to ascribe responsibility to themselves are associated with increases in selfless helping tendencies. Furthermore, both early adolescents and middle adolescents who report altruistic tendencies were less likely to report aggressive tendencies. Those latter findings were consistent with previous research (see Crick \& Dodge, 1994; Eisenberg \& Fabes, 1998) that indicated that aggressive individuals and altruistic individuals might differ on emotion regulation skills, sociocognitive skills, and social ecology (e.g., family affective climate, adolescents' experiences with their parents, peer support). It might be expected that altruistic individuals would be adept at emotion regulation and sociocognitive functioning and that those skills might facilitate consideration of the needs of others who are distressed.

Consistent with the hypotheses, in general, adolescents who reported being more helpful in emotionally evocative contexts were more likely to use internalized prosocial moral reasoning, to take another's perspective (although nonsignificant for middle adolescents), and to be adept at under- 
standing another's situation. Furthermore, this type of helping was associated with higher levels of sympathy and ascription of responsibility but not to personal distress. Taken together, those findings were consistent with research that has shown that there might be an optimal level of emotional sensitivity that facilitates helping in emotionally evocative situations but does not inhibit sociocognitive functioning (Carlo, Allen, \& Buhman, 1999).

As expected, helping in front of others was related to approval-oriented moral reasoning both for early adolescents and middle adolescents. Furthermore, that type of helping was not associated with any of the other cognitive, emotive, or trait variables. Those findings were consistent with the notion that gaining the approval of others might be the primary motive for adolescents who help frequently in front of an audience. Indeed, approval-oriented moral reasoning was not significantly related to any of the other PTM-R subscales except negatively to altruism. That indicates that altruistically inclined adolescents might be less concerned with gaining stature from their actions. Those findings were consistent with previous empirical findings that adolescents who appear most concerned with gaining others' approval in prosocial moral situations are more likely to aggress toward others. It is interesting that gaining other people's approval is also characteristic of juvenile delinquents (Carlo, Koller, \& Eisenberg, 1998). Research might begin to focus on whether there is a threshold for being too concerned about approval from others that places adolescents at high risk for problem behaviors.

Helping in emergency or dire situations was associated with less hedonistic prosocial moral reasoning and higher levels of sympathy, perspective taking, and empathic accuracy for both early adolescents and middle adolescents. However, in early adolescence, dire helping was linked to hedonistic prosocial moral reasoning. In contrast, in middle adolescence, dire helping was linked to lower levels of approval-oriented prosocial moral reasoning and to higher levels of needs-oriented and internalized prosocial moral reasoning and ascription of responsibility. That contrasting pattern of relations indicated that hedonistic concerns are primary to determine helping in emergency situations in early adolescence, whereas middle adolescents might rely more on other-oriented moral reasoning abilities and their notions about responsibility to determine their response in those situations. Further research (perhaps using experimental designs) is needed to examine those possibilities. Middle adolescents who reported tendencies to help anonymously were less hedonistic in their moral reasoning. It might be expected that helping under those circumstances would require good perspective-taking and empathic-accuracy skills as well as less concern with self desires and needs. However, anonymous helping was associated significantly to empathic accu- racy only in early adolescence and there were no significant relations between perspective taking and anonymous helping. Because perspective taking and moral reasoning skills are developing still during early adolescence (Carlo et al., 1992), perhaps other traits or situational factors are more relevant to predicting anonymous helping during adolescence. Indeed, the fact that middle adolescents reported more anonymous and altruistic helping than did early adolescents is consistent with the notion that anonymous and altruistic helping might require relatively more sophisticated perspective taking (e.g., perspective taking that requires abstraction, forethought, hypothetical deductive reasoning) than the other types of helping. Further research might be used to examine whether age differences in sociocognitive skills (such as moral reasoning) could account for age differences in anonymous and altruistic forms of helping.

Both early adolescents and middle adolescents who reported more emotional sensitivity and self responsibility were more likely to report higher levels of compliant helping. In contrast, higher levels of hedonistic prosocial moral reasoning were linked to lower levels of compliant helping. Because compliant helping demands respect for others (including authority figures), it might be expected that adolescents who are compliant also are sensitive to the needs of others and have a high sense of responsibility. Furthermore, adolescents who prefer hedonistic moral reasoning are concerned about their own needs and desires and those needs are likely to conflict with the needs of people who ask for their help. It is interesting that higher levels of perspective taking and empathic accuracy were related to higher levels of compliant helping tendencies particularly for early adolescents. Perhaps those sociocognitive skills facilitate compliant helping tendencies in early adolescence but because those skills are developed better by middle adolescence, those skills are less relevant in predicting that type of helping later in adolescence.

As expected, personal distress, in contrast to sympathy, was not associated significantly with any of the six helping types for both early adolescents and middle adolescents (with the exception of altruism for middle adolescents). Thus, emotional oversensitivity did not seem to predict helping (except perhaps when it is difficult to escape from the situation; see Batson, 1991) and might hinder altruistic helping because the focus of distressed individuals would be on self needs rather than on the needs of others (see Eisenberg \& Fabes, 1998).

There were a number of interesting relations between the PTM-R subscales and the other measures of prosocial behavior. Middle, but not early, adolescents who were rated by their teachers as relatively more helpful and generous were more likely to describe themselves as more helpful in emotional situations. However, teacher ratings of generosity and helpfulness 
were not significantly related with the other types of helping. The overall lack of significant relations between teachers' ratings of adolescents' behavior and the PTM-R subscales indicates a lack of strong evidence for convergent validity using a teacher rating measure of helpfulness. However, it is important to note that teachers are privy to only a small sample of adolescents' prosocial behaviors-especially in middle-level school and high school (adolescents have different teachers for each course and the classroom activities tend to be structured, minimizing variability in helping behaviors). Indeed, it is common to find modest magnitudes of effect size between teacher ratings and self ratings of children's prosocial behaviors (e.g., Roberts \& Strayer, 1996).

Alternatively, as mentioned in the introduction, it might be that generosity and helpfulness ratings of prosocial behaviors are not distinct sufficiently to better predict the six specific types of helping reflected in the PTM-R. Indeed, in the present study, there was an overall significant relation between a composite of the PTM-R and teachers' ratings of generosity and helpfulness for early adolescents (but not middle adolescents). That pattern of findings supports the contention that global measures of prosocial behaviors might be significantly and more consistently associated with other global measures of prosocial behaviors, particularly during early adolescence when adolescents might be less likely to differentiate among differing forms of helping. Consistent with that latter contention, there were significant interrelations among the PTM-R subscales (except between public and compliant) for early adolescents but fewer such relations for middle adolescents. It might be expected that adolescents differentiate more among forms of helping as higher levels of cognitive development are acquired and as adolescents are exposed to, and engage in, differing forms of helping.

The pattern of the relations between the PTM-R subscales and the global index of prosocial behavior showed convergent validity evidence. In general, the index of global prosocial behavior was significantly and positively related with all the subscales of the PTM-R except altruism and public helping (for middle adolescents). An examination of the items from this commonly used index of global prosocial behavior indicates that the scale does tap into a wide variety of helping behaviors. Some of the items include carrying books for a stranger (similar to compliant helping), helping a person cross the street (similar to public helping), donating money to a charity (similar to anonymous helping), and helping someone who is hurt (similar to emotional and dire helping). However, there were no items that seemed to tap into helping others with little or no regard for self consequences (i.e., altruism). Thus, unlike this commonly used global index of self-reported prosocial behavior, the PTM-R appears to tap into a type of helping (i.e., altruism) that has been the focus of interest for many scholars.

Because of the importance of understanding both the development of aggressive behaviors and prosocial behaviors, there is a growing interest in the link between those behaviors. The present findings showed a moderate negative relation between aggression and compliant and altruistic tendencies (even though the indices shared method variance because both indices were self-report measures). Those findings were consistent with researchers' previous findings that there was a modest relation between aggressive behaviors and prosocial behaviors (e.g., Crick \& Gropeter, 1995; see Eisenberg \& Fabes, 1998). Taken together, those findings indicate that aggression and helping are not just the flip side of each other-that it is important to distinguish between the two constructs. Adolescents who are aggressive are not necessarily less helpful and adolescents who are helpful are not necessarily less aggressive. Furthermore, a reduction in aggressive and violent acts might not equate necessarily to an increase in prosocial behaviors (and vice versa). Thus, program evaluators of intervention programs designed to promote prosocial behaviors and/or reduce aggressive behaviors should consider separately assessing prosocial outcomes and aggressive outcomes to better understand the effectiveness of the program on those distinct outcomes.

Consistent with cognitive-developmental and gender socialization theories, there were a number of age and gender differences in prosocial tendencies. For example, adolescent girls and middle adolescents more frequently described themselves as altruistic than did adolescent boys and younger adolescents. The gender difference was consistent with the Fabes et al. (1999) meta-analysis findings that revealed that strong gender differences in prosocial behavior are evident during adolescence. That might be due, in part, to a consolidation of socialization experiences from childhood that encourage the expression of prosocial tendencies for girls and discourage the expression of those tendencies for boys (Brody, 1985). Furthermore, these gender differences might become stronger for adolescents as their perceptions of self-concept change due to physical maturation processes and social comparison processes (Fabes et al., 1999).

In contrast, boys reported more public types of helping than did girls. That finding was consistent with previous findings that men tend to help more often in public situations than do women (Eagly \& Crowley, 1986) and that adolescent boys exhibit more concern for gaining other people's approval than do adolescent girls (Carlo et al., 1992, 1996). The finding that middle adolescents generally reported being more helpful than did early adolescents 
might reflect increasing cognitive-development skills and increasing exposure to helping opportunities during adolescence.

There were several limitations in the present study. First, the sample was relatively homogeneous with respect to race and ethnicity. The findings might not be generalizable to more diverse samples. Further studies will be needed to examine these findings in larger and more diverse populations. This might enable researchers to examine whether the current findings differ by demographic variables (e.g., gender, ethnicity) and to examine the structure of the PTM-R with confirmatory factor analyses. Second, most of the measures were self-report, which might introduce self-presentational biases and verbal skill confounds. However, as expected, the weak relations between social desirability and vocabulary scores and the PTM-R indicated that responses were not influenced strongly by their desire to impress others or by vocabulary skills. Third, longitudinal research is needed to confirm and replicate the age-related findings in the present study. Furthermore, because there is sparse research on the correlates of specific types of prosocial behaviors during adolescence, the present findings should be interpreted with caution until further research is conducted.

In summary, the present findings yielded evidence that the PTM-R has adequate psychometric properties and that it can be used with early adolescents and middle adolescents from the United States. Specific types of helping behaviors had a unique pattern of relations to sociocognitive, socioemotive, and social behavior measures and those relations differed across early adolescence and middle adolescence. Those findings indicate that research on specific forms of helping behaviors might be useful to account for previously shown individual differences in prosocial behaviors during adolescence.

\section{APPENDIX}

Below are sentences that might or might not describe you. Please indicate how much each statement describes you by using the scale below.

$\begin{array}{ccccc}\text { Does Not } & \text { Describes } & \text { Somewhat } & & \text { Describes } \\ \text { Describe } & \text { Me } & \text { Describes } & \text { Describes } & \text { Me } \\ \text { Me At All } & \text { A Little } & \text { Me } & \text { Me Well } & \text { Greatly } \\ 1 & 2 & 3 & 4 & 5\end{array}$

1. I can help others best when people are watching me.

2. It makes me feel good when I can comfort someone who is very upset.

3. When other people are around, it is easier for me to help others in need.

4. I think that one of the best things about helping others is that it makes me look good.
5. I get the most out of helping others when it is done in front of other people. 6. I tend to help people who are in a real crisis or need.

7. When people ask me to help them, I don't hesitate.

8. I prefer to donate money without anyone knowing.

9. I tend to help people who are hurt badly.

10. I believe that donating goods or money works best when I get some benefit.

11. I tend to help others in need when they do not know who helped them.

12. I tend to help others especially when they are really emotional.

13. Helping others when I am being watched is when I work best.

14. It is easy for me to help others when they are in a bad situation.

15. Most of the time, I help others when they do not know who helped them.

16. I believe I should receive more rewards for the time and energy I spend on volunteer service.

17. I respond to helping others best when the situation is highly emotional.

18. I never wait to help others when they ask for it.

19. I think that helping others without them knowing is the best type of situation.

20. One of the best things about doing charity work is that it looks good on my resume.

21. Emotional situations make me want to help others in need.

22. I often make donations without anyone knowing because they make me feel good.

23. I feel that if I help someone, they should help me in the future.

24. I often help even if I don't think I will get anything out of helping.

25. I usually help others when they are very upset.

\section{REFERENCES}

Achenbach, T. M. (1991). Manual for the Child Behavior Checklist/4-18 and 1991 Profle. Burlington: University of Vermont, Department of Psychiatry.

Bandura, A. (1986). Social foundations of thought and action: A social cognitive theory. Englewood Cliffs, NJ: Prentice Hall.

Batson, C. D. (1991). The altruism question: Toward a social psychological answer. Hillsdale, NJ: Lawrence Erlbaum.

Blasi, A. (1980). Bridging moral cognition and moral action: A critical review of the literature. Psychological Bulletin, 88, 1-45.

Borgatta, E. P., \& Corsini, R. J. (1960). The Quick Word Test (QWT). Journal of Educational Research, 54, 15-20.

Brody, L. R. (1985). Gender differences in emotional development: A review of theories and research. Journal of Personality, 53, 102-149.

Carlo, G., Allen, J., \& Buhman, D. (1999). Facilitating and disinhibiting prosocial behaviors: The nonlinear interaction of trait perspective taking and trait personal distress on volunteering. Basic and Applied Social Psychology, 21, 189-197.

Carlo, G., Eisenberg, N.,\&Knight, G. P. (1992). An objective measure of adolescents' prosocial moral reasoning. Journal of Research on Adolescence, 2, 331-349.

Carlo, G., Eisenberg, N., Troyer, D., Switzer, G., \& Speer, A. L. (1991). The altruistic personality: In what contexts is it apparent? Journal of Personality and Social Psy- 
chology, 61, 450- 458.

Carlo, G., Fabes, R. A., Laible, D., \& Kupanoff, K. (1999). Early adolescence and prosocial/ moral behavior II: The role of social and contextual influences. Journal of Early Adolescence, 19, 133-147.

Carlo, G., Koller, S., \& Eisenberg, N. (1998). Prosocial moral reasoning in institutionalized delinquent, orphaned, and noninstitutionalized Brazilian adolescents. Journal of Adolescent Research, 13, 363-376.

Carlo, G., Koller, S. H., Eisenberg, N., Da Silva, M. S., \& Frohlich, C. B. (1996). A cross-national study on the relations among prosocial moral reasoning, gender role orientations and prosocial behaviors. Developmental Psychology, 32, 231-240.

Carlo, G., \& Randall, B. A. (2001). Are all prosocial behaviors equal? A socioecological developmental conception of prosocial behavior. In F. Columbus (Ed.), Advances in psychology research, Volume II (pp. 151-170). New York: Nova Science.

Carlo, G.,\&Randall, B. A. (2002). The development of a measure of prosocial behaviors for late adolescents. Journal of Youth and Adolescence, 31, 31-44.

Carlo, G., Roesch, S. C., \& Melby, J. (1998). The multiplicative relations of parenting and temperament to prosocial and antisocial behaviors in adolescence. Journal of Early Adolescence, 18, 148-170.

Consortium on the Promotion of Social Competence. (1994). The school-based promotion of social competence: Theory, research, practice, and policy. In R. J. Haggerty, L. R. Sheroud, N. Garmezy, \& M. Rutter (Eds.), Stress, risk, and resilience in children and adolescents: Processes, mechanisms, and interventions (pp. 268-316). Cambridge, UK: Cambridge University Press.

Crick, N., \& Dodge, K. A. (1994). A review and reformulation of social information processing mechanisms in children's social adjustment. Psychological Bulletin, 115, 74-101.

Crick, N. R., \& Gropeter, J. K. (1995). Relational aggression, gender, and social-psychological adjustment. Child Development, 66, 710-722.

Crick, N. R., \& Nelson, D. A. (1999). Rose colored glasses: Examining the social information-processing of prosocial young adolescents. Journal of Early Adolescence, 19, 17-38.

Crowne, D. P., \& Marlowe, D. (1964). The approval motive. New York: Wiley.

Davis, M.H. (1983). Measuring individual differences in empathy: Evidence for a multidimensional approach. Journal of Personality and Social Psychology, 44, 113-126.

Davis, M. H., \& Franzoi, S. (1991). Stability and change in adolescent self-consciousness and empathy. Journal of Research in Personality, 25, 70-87.

Eagly, A. H., \& Crowley, M. (1986). Gender and helping behavior: A meta-analytic review of the social psychological literature. Psychological Bulletin, 100, 283-308.

Eisenberg, N. (1986). Altruistic emotion, cognition, and behavior. Hillsdale, NJ: Lawrence Erlbaum.

Eisenberg, N., Cameron, E., Tryon, K., \& Dodez, R. (1981). Socialization of prosocial behavior in the preschool classroom. Developmental Psychology, 71, 773-782.
Eisenberg, N., Carlo, G., Murphy, B., \& Van Court, P. (1995). Prosocial development in late adolescence: A longitudinal study. Child Development, 66, 1179-1197.

Eisenberg, N., \& Fabes, R. A. (1998). Prosocial development. In W. Damon (Series Ed.) \& N. Eisenberg (Vol. Ed.), Handbook of child psychology, Vol. 3: Social, emotional, and personality development (5th ed., pp. 701-778). New York: John Wiley.

Eisenberg, N., Guthrie, I. K., Murphy, B. C., Shepard, S. A., Cumberland, A., \& Carlo, G. (1999). Consistency and development of prosocial dispositions: A longitudinal study. Child Development, 70, 1360-1372.

Estrada, P. (1995). Adolescents' self-reports of prosocial responses to friends and acquaintances: The role of sympathy-related cognitive, affective and motivational processes. Journal of Research on Adolescence, 5, 173-200.

Fabes, R. A., Carlo, G., Kupanoff, K., \& Laible, D. (1999). Early adolescence and prosocial/ moral behavior I: The role of individual processes. Journal of Early Adolescence, 19, 5-16.

Fletcher, A. C., Elder, G. E., Jr.,\&Mekos, D. (2000). Parental influences on adolescent involvement in community activities. Journal of Research on Adolescence, 10, 29-48.

Hoffman, M. L. (1991). Empathy, social cognition, and moral action. In W. M. Kurtines \& J. L. Gewirtz (Eds.), Handbook of moral behavior and development, Volume 1: Theory (pp. 275- 301). Hillsdale, NJ: Lawrence Erlbaum.

Ickes, W., Bissonnette, V., Garcia, S., \& Stinson, L. L. (1990). Implementing and using the dyadic interaction paradigm. Thousand Oaks, CA: Sage.

Independent Sector. (1999). Giving and volunteering in the United States: Findings from a national survey, 1998. Washington, DC: Independent Sector Publications.

Johnson, R. C., Danko, G. P., Darvill, T. J., Bochner, S., Bowers, J. K., Huang, Y.-H. Park, J. Y., Pecjak, V., Rahim, A. R. A.,\&Pennington, D. (1989). Cross-cultural assessment of altruism and its correlates. Personality and Individual Differences, 10 , 855-868.

Knight, G. P., Johnson, L. G., Carlo, G., \& Eisenberg, N. (1994). A multiplicative model of the dispositional antecedents of a prosocial behavior: Predicting more of the people more of the time. Journal of Personality and Social Psychology, 66, 178-183.

Laible, D. J., Carlo, G., \& Raffaelli, M. (2000). The differential relations of parent and peer attachment to adolescent adjustment. Journal of Youth and Adolescence, 29, 4559.

Roberts, W., \& Strayer, J. (1996). Empathy, emotional expressiveness, and prosocial behavior. Child Development, 67, 449-470.

Rushton, J. P., Chrisjohn, R. D., \& Fekken, G. C. (1981). The altruistic personality and the self-report altruism scale. Personality and Individual Differences, 2, 1-11.

Schroeder, D. A., Penner, L. A., Dovidio, J. F., \& Piliavin, J. A. (1995). The psychology of helping and altruism: Problems and puzzles. New York: McGraw-Hill.

Schwartz, S. H. (1968).Words, deeds, and the perception of consequences and responsibility in social situations. Journal of Personality and Social Psychology, 10, 232-242. 
Schwartz, S. H., \& Howard, J. A. (1984). Internalized values as motivators of altruism. In E. Staub, D. Bar-Tal, J. Karylowski, \& J. Reykowski (Eds.), The development and maintenance of prosocial behavior: International perspectives on positive development (pp. 229- 255). New York: Plenum.

Selman, R. L. (1980). The growth of interpersonal understanding: Developmental and clinical analyses. New York: Academic Press.

Staub, E. (1978). Positive social behavior and morality: Social and personal influences (Vol. 1). New York: Academic Press.

Thoma, S. J., Rest, J. R., \& Davison, M. L. (1991). Describing and testing a moderator of the moral judgement and action relationship. Journal of Personality and Social Psychology, 61, 659-669.

Tomlinson-Keasey, C., \& Keasey, C. B. (1974). The mediating role of cognitive development in moral judgement. Child Development, 45, 291-298.

Weinberger, D. A. (1991). Social-emotional adjustment in older children and adults: I. Psychometric properties of the Weinberger Adjustment Inventory. Unpublished manuscript, Case Western Reserve University.

Weinberger, D. A. (1995). Distress and self-restraint as measures of adjustment across the lifespan: Confirmatory factor analyses in clinical and non-clinical samples. Unpublished manuscript, Case Western Reserve University.

Weinberger, D. A., \& Bartholomew, K. (1996). Social-emotional adjustment and patterns of alcohol use among young adults. Journal of Personality, 64, 495-527.

Weinberger, D. A., \& Gomes, M. E. (1995). Changes in daily mood and self-restraint among uncontrolled preadolescents: A time-series analysis of acting out. Journal of the American Academy of Child and Adolescent Psychiatry, 34, 1473-1482.

Requests for reprints should be addressed to Gustavo Carlo, Department of Psychology, University of Nebraska-Lincoln, Lincoln, NE 68588-0308; e-mail: gcarlo@unl.edu. 